\title{
Determination of the Operating Regimes of CHP Turbines with Stage-wise Heating of District Heating System Water
}

\author{
Zvonimir Guzović $^{1, *}$, Perica Jukić ${ }^{2}$, Dražen Lončar ${ }^{1}$ \\ ${ }^{1}$ University of Zagreb, Faculty of Mechanical Engineering and Naval Architecture, Zagreb, Croatia \\ ${ }^{2}$ HEP-Proizvodnja d.o.o., Member of HEP Group, Thermal Power Plants, Zagreb, Croatia \\ *Corresponding author. Tel: +385 16168532, Fax: +385 16156940,E-mail: zvonimir.guzovic@fsb.hr
}

\begin{abstract}
Today, the district heating (DH) is often based on cogeneration power plants with steam turbines for combined heat and power production (CHP turbines and plants). As the heat is supplied as steam with the given parameters, so CHP steam turbines are realized with controlled steam extractions. In case of stage-wise heating of the district heating system water the entire heating is realized in a number of successively connected water heaters by steam extracted from the turbine. The aim of stage-wise heating is additional production of electricity, because the heating steam extracted for the first stage in the direction of system water flow has lower pressure than for the second stage. In this paper the results of determination of heat-supply operating regime with twostage heating of the system water for CHP turbine of $120 \mathrm{M} \mathrm{W}$ power (T-100-110/130-3) installed in Cogeneration Power Plants Zagreb (TE-TO Zagreb), obtained by means of original developed computer program, will be presented both in analytic form (by equations) and by means of diagrams.
\end{abstract}

Keywords: Cogeneration, CHP turbine and power plants, Operating regimes, District heating (DH), Stage-wise heating

\section{Nomenclature}

C specific heat. $J \cdot \mathrm{kg}^{-1} \cdot \mathrm{K}^{-1}$

$\vartheta \quad$ temperature. .$^{0} \mathrm{C}$

$\dot{E}_{1}$ specific production of electricity by heatsupply flow rate at one-stage heating. $M W_{e} \cdot M W_{t o}{ }^{-1}$

$h_{z v v 1}$ enthalpy of condensate of the upper heating extraction. ...$k J \cdot k g^{-1}$

$h_{z v v 1}$ enthalpy of condensate of the lower heating extraction ..$k J \cdot k g^{-1}$

$q$ flow rate $\mathrm{kg} \cdot \mathrm{s}^{-1}$

\author{
Subscripts \\ $m$ measured data obtained on the actual \\ turbine during operation \\ prog calculation results obtained by the \\ program or equation \\ v.z. ambient air \\ $w$ system water
}

$\eta_{g . m}$ electrical and mechanical efficiency ......... -

\section{Introduction}

District heating is a system for distributing heat generated in a centralized location for residential, public and industrial heating requirements such as space heating and water heating in a large area. The heat is obtained from a cogeneration power plant burning fossil fuels (but now increasingly from renewable energy sources such as biomass, as well as nuclear power). District Heating $(\mathrm{DH})$ based on cogeneration power plants with simultaneous production of heat and electricity (also called Combined Heat and Power - CHP) provides high system efficiency, low emissions and higher degree of fuel flexibility than single-purpose energy systems (e.g. localized boilers).

The number of DH systems associated with CHP plants has been increasing in the last decade due to their energy savings (up to $30 \%$ ), environmental improvements and reduction of life cycle costs [1]. New CHP plants have a power-to-heat ratio of about 1.0 compared with 0.40.5 for traditional condensing steam turbines. However, only $13 \%$ of electricity generated in EU today is based on CHP; however, it is regarded by the European Commission as a 
possible way to improve energy efficiency and reduce the environmental impact. DH plays a minor role in the overall European energy system today, but it is significant in Denmark, Finland and Sweden [2].

Therefore, this paper pays special attention to DH based on C HP turbines (plants). The advantages of stage-wise heating of the district heating system water over one-stage will be presented. With the aim of studying further the possibilities of energy efficiency increase, first of all, by improvement of an operating regime in specific conditions of simultaneous production of power and heat, an original computational program for determination of the operating regime diagrams for different types of CHP turbines has been developed [3]. The program is based on operating regime diagrams (i.e. of energy characteristics), manufacturers' data, results of normative measurements and data obtained during exploitation. The results of calculation by means of the developed program will be presented for CHP turbine of $120 \mathrm{MW}$ power installed in the Cogeneration Plant Zagreb (TE-TO Zagreb) for the heat-supply regime with two-stage heating of district heating system water.

\section{Characteristics of CHP turbines and CHP plants}

CHP steam turbines are characterized by a diversity of probable operating regimes which can be divided into two groups depending on the heating load: condensing regimes and heatsupply regimes. In a condensing regime, the steam flow rate to controlled extraction is equal to zero. This regime is identical to the operation of a condensing turbine. Heat-supply regimes are characterized by a certain heating load carried by the turbine. A heat-supply regime may be carried out by either heating or electric schedule depending on the nature of the heating load. In operation by heating schedule, the electric power is determined by the heating load and cannot be changed without changing accordingly the heat consumption. Under such conditions, a certain (minimal) quantity of steam is however passed through the low-pressure part of the turbine in order to absorb the heat of friction of the rotating elements. In operation by an electric schedule it is typical that turbine carries a certain heating load which limits the possibility of reducing the electric power blow to a certain minimum, but it is possible to increase the electric power up to the maximum by passing more steam to the condenser.

Thermodynamic characteristics, design, techno-economic indicators and other characteristics of CHP turbines and plants are described in more detail in [3-9].

The heating load is characterized by significant changes during the year and its value changes depending on the temperature of the ambient air. The maximum output of heat is at the minimal calculation temperature of ambient air which is determined on the basis of climatic conditions. During the summer period there will be only the heating load for the heating of hot water, which accounts for on the average two thirds of the mean value in winter [3-4].

The heating load and parameters of the district heating system water are connected by the equation

$Q_{t o}^{T E}=q_{w} c_{w}\left(\vartheta_{p o l}-\vartheta_{p o v}\right)$

where $Q_{t o}^{T E}$ is the heating load of the cogeneration power plant, $\vartheta_{p o l}$ and $\vartheta_{p o v}$ are the starting and the returned temperature of the system water. 
The change in the starting and returned temperature of the system water in dependence on the ambient air temperature is called a temperature diagram. Fig. 1 shows the temperature diagram constructed for the climate conditions in the city of Zagreb [3].

The steam of heat-supply turbine extractions is used for covering the heating load. Uniformity of load of turbine heat-supply extraction can be achieved if the extraction is used only for covering the base part of the diagram, and its peak is covered e.g. by peak hot-water boilers, Fig. $1[3]$.

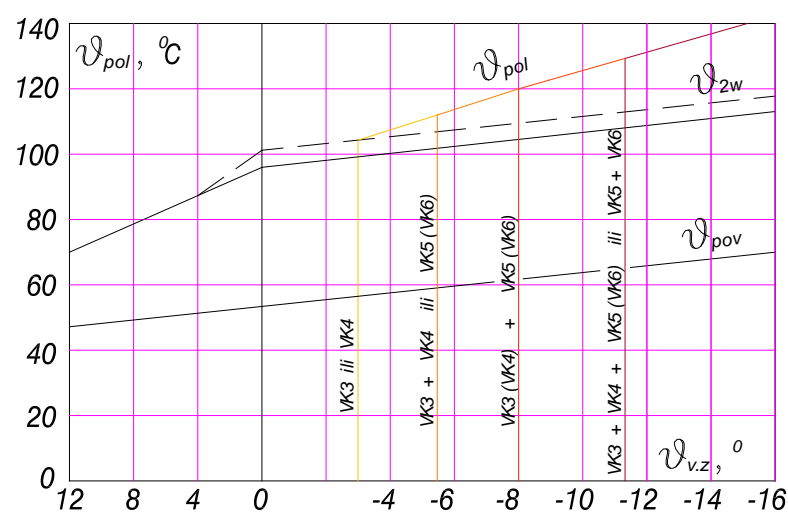

Fig. 1. Temperature diagram of the district heating system: VK3, 4, 5, 6 - peak bot-water boilers;

-- -- -- - using the heat of steam leaving the condquser [3]

The ratio of heat load of the turbine heat-supply extractions and the total heating load of the cogeneration plant at minimal calculation temperature of ambient air is called the coefficient of heating $\alpha_{T E}$ [3-4]. With $\alpha_{T E}<1$ part of the heating load is covered for example, by peak hot-water boilers, and in a thermal power plant with cogeneration also separate production of heat appears.

The temperature diagram of the district heating system and accepted coefficient of heating determine the starting temperature of the system water after regenerative heaters $\vartheta_{2 w}$ which are fed with steam from the turbine heat-supply extractions. At the minimal temperature of the ambient air, the value is determined from the equation

$\vartheta_{2 w}=\vartheta_{p o v}+\left(\vartheta_{p o l}-\vartheta_{p o v}\right) \alpha_{T E}$

For any given ambient air temperature is

$\vartheta_{2 w}=\vartheta_{p o v}+\frac{Q_{t o}^{T E}}{q_{w} C_{w}}$

For the heat-supply period, when the peak boiler is switched off and the entire heat load is covered by turbine heat-supply extraction

$\vartheta_{2 w}=\vartheta_{p o l}$

In case of turbines with controlled extractions of steam, efficiency increase can be achieved by using heat of the steam leaving the condenser [3-6]. 


\section{Stage-wise heating of district heating system water}

In case of stage-wise heating of district heating system water (Fig. 2) the whole heating is realised in a number of successively connected water heaters by steam extracted from the turbine. The required pressure of the extracted steam is determined by the temperature of water at the exit from each heating stage. The steam, extracted for the first stage in the direction of the system water flow, has lower pressure than for the second stage, which ensures additional production of electricity in comparison with one-stage heating, when the whole steam is extracted at a pressure which is determined by the final heating temperature of the system water. Therefore, the aim of stage-wise heating is additional production of electricity by means of the heating steam [3-4].

Effectiveness of stage-wise heating of the system water is determined by a large number of factors, including the primary ones: the number of heating stages and the distribution of the heating load between stages; heating load values, flow rate and temperatures of system water and their change during the year; dimensions, design and temperature diagram of district heating system, climatic conditions and coefficient of heating, parameters of fresh steam, design of turbine and auxiliary plant, etc. [3-6].

Fig. 2 presents the stage-wise heating of the system water (two-stage) which corresponds to the type scheme of the modern CHP turbines with the following characteristics:

- $\quad$ System water heaters are supplied by steam from extractions of one turbine.

- There are no governing valves on the steam pipelines of extractions.

- The flow rate of the system water through all heating stages is equal.

- Condensate from single heaters of stage-wise heating by pumps is carried into the line of regenerative heating of feed water.

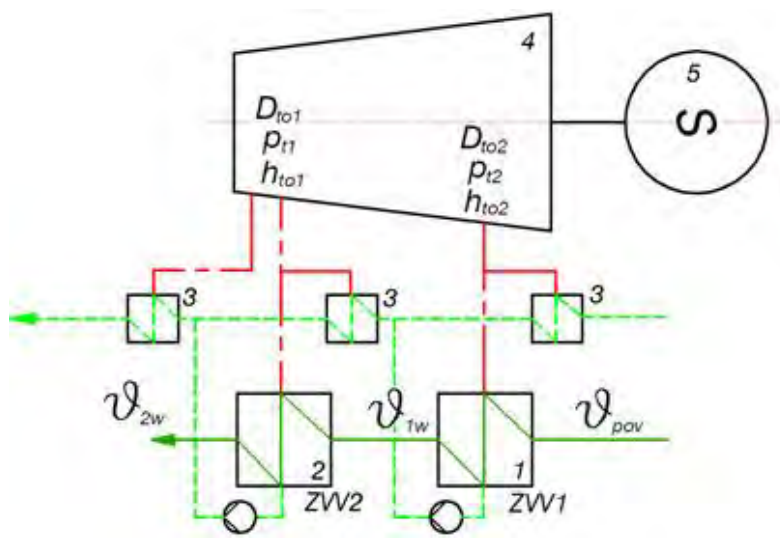

Fig. 2. Principal diagram of a CHP turbine with two heating steam extractions: 1- the lower heating extraction; 2- the upper heating extraction; 3- regenerative heaters; 4- turbine, 5- generator; $D_{t o 1}, p_{t 1}$, $h_{\text {to1 }}$ - flow rate, pressure and enthalpy of the upper heating extraction; $D_{t o 2}, p_{t 2}, h_{\text {to2 }}$ - flow rate, pressure and enthalpy of the lower heating extraction; $\vartheta_{p o v}, \vartheta_{1 w}, \vartheta_{2 w}-$ temperatures of the returned system water, and after the lower and upper heating extractions

At transition from one-stage on two-stage heating of district heating system water, with unchanged heating load, the additional production of electricity $\Delta P$ is

$\Delta P=D_{t o 2}\left\lfloor\left(h_{t o 1}-h_{t o 2}\right) \eta_{g . m}+\dot{E}_{1}\left(h_{z v v 2}-h_{z v v 1}\right)\right\rfloor$

and the additional specific production of electricity $\Delta \dot{E}_{2}$ by means of the heating steam 
$\Delta \dot{E}_{2}=\frac{D_{t o 2}}{Q_{t o}^{T E}}\left[\left(h_{t o 1}-h_{t o 2}\right) \eta_{g \cdot m}+\dot{E}_{1}\left(h_{z v v 2}-h_{z v v 1}\right)\right]$

At a two-stage heating of district heating system water by scheme shown in Fig. 2 the optimum increase of water enthalpy is equal in both stages of heating [3-4].

\section{Heat-supply operating regime of T-100-110/130-3 CHP turbine: two-stage heating of district heating system water}

For T-100-110/130-3 CHP turbine on the basis of theoretical principles, the design data obtained from the manufacturer of the UTMZ-Russia turbine, the data of normative and remaining measurements performed in the Cogeneration Plant Zagreb and on the basis of data obtained during exploitation, the uniform operating regime diagram has been designed in the graphical form in which all turbine working regimes are presented [3]. After that, the obtained operating regime diagram in graphical form is completely translated into the analytic form, i.e. described by analytic dependences in the form of energy characteristics. The energy characteristics are built into the algorithm of original computer program, by means of which it is possible to calculate all the operating regimes of T-100-110/130-3 CHP turbine [3]. These are the condensing operating regime and the heat-supply regimes with one-stage, two-stage and three-stage heating of district heating system water.

As in this paper the object of investigation is stage-wise heating of district heating system water, only the results for the heat-supply operating regimes with two-stage heating will be presented: both in analytic form (by equations) and by means of diagrams [3]. The heatsupply regime with two-stage heating is used when the need for heat is minimally $120 \mathrm{MW}$, and when the daily temperature is below $5^{\circ} \mathrm{C}$. The functional dependences are obtained on the basis of results from the region of CHP turbine heat-supply operating regimes with two-stage heating [3].

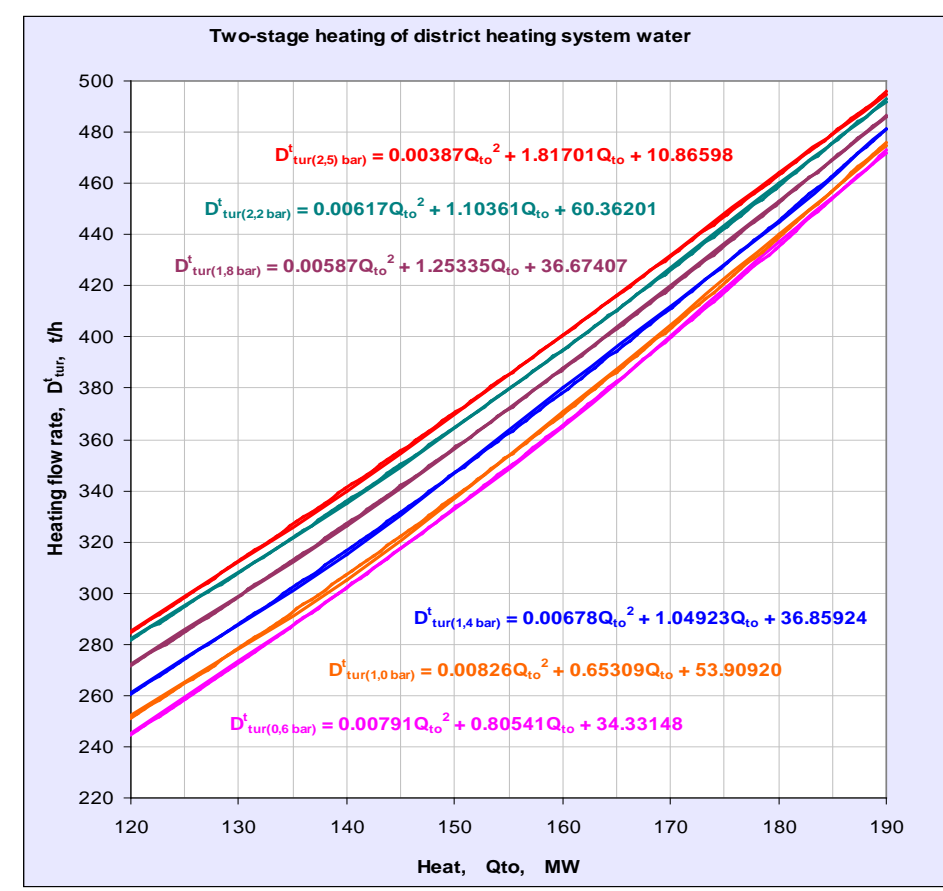

Fig. 3. Heat-supply operating regime of the T-100-110/130-3 CHP turbine - dependence of heatsupply flow rate on heat and on the pressure in the upper heating extraction at two-stage heating of system water [3] 
The dependence of heat-supply flow rate $D_{t u r_{d v o}}^{t}$ on heat $Q_{t o}^{d v o}$ and on the pressure in the upper heating extraction at two-stage heating (index $d v o$ in the following equations) of system water is presented in Fig. 3, and can be described by the following equation

$$
D_{t u r_{d v o}}^{t}=a_{D}^{d v o}\left(Q_{t o}^{d v o}\right)^{2}+b_{D}^{d v o} Q_{t o}^{d v o}+c_{D}^{d v o}
$$

The dependences of increasing parameters of the heat-supply flow rate $a_{D}^{d v o}, b_{D}^{d v o}, c_{D}^{d v o}$ on the pressure in the upper heating extraction $p_{t 1}$ at two-stage heating of the system water can be described by the following equations [3]

$$
\begin{aligned}
& a_{D}^{d v o}=-0.004119 p_{t 1}^{5}+0.025966 p_{t 1}^{4}-0.05743 p_{t 1}^{3}+0.051103 p_{t 1}^{2}--0.015333 p_{t 1}+0.008073 \quad \text { (7.a) } \\
& b_{D}^{d v o}=1.259133 p_{t 1}^{5}-7.872131 p_{t 1}^{4}++17.222733 p_{t 1}^{3}-15.060567 p_{t 1}^{2}+4.186251 p_{t 1}+0.917671 \quad \text { (7.b) } \\
& c_{D}^{d v o}=-92.54839 p_{t 1}^{5}+572.1809 p_{t 1}^{4}-1237.44892 p_{t 1}^{3}+1072.77346 p_{t 1}^{2}-273.77944 p_{t 1}+12.73158 \text { (7.c) }
\end{aligned}
$$

The dependence of electricity produced by heat-supply flow $P_{e_{d v o}}^{t}$ on the heat $Q_{t o}^{d v o}$ and on the pressure in the upper heating extraction at two-stage heating of the system water is presented in Fig. 4, and can be described by the following equation

$$
P_{e_{d v o}}^{t}=a_{P}^{d v o}\left(Q_{t o}^{d v o}\right)^{2}+b_{P}^{d v o} Q_{t o}^{d v o}+c_{P}^{d v o}
$$

The dependences of increasing parameters of the electricity produced by heat-supply flow rate $a_{P}^{d v o}, b_{P}^{d v o}, c_{P}^{d v o}$ on the pressure in the upper heating extraction $p_{t 1}$ at two-stage heating of the system water can be described by the following equations for the pressure range 0.6-1.4 bar [3]

$$
\begin{aligned}
& a_{P}^{d v o}=0.000428 p_{t 1}^{2}-0.001145 p_{t 1}+0.001499 \\
& b_{P}^{d v o}=0.100437 p_{t 1}^{2}+0.212762 p_{t 1}+0.386902 \\
& c_{P}^{d v o}=4.4641 p_{t 1}^{2}-8.9851 p_{t 1}-7.5197
\end{aligned}
$$

and for the pressure range 1.4-2.5 bar by the following equations [3]

$$
a_{P}^{d v o}=0.01746 p_{t 1}^{5}-0.172862 p_{t 1}^{4}+0.673167 p_{t 1}^{3}-1.287444 p_{t 1}^{2}+1.208139 p_{t 1}-0.444287
$$

$$
b_{P}^{d v o}=-6.03471 p_{t 1}^{5}+59.848 p_{t 1}^{4}-233.57253 p_{t 1}^{3}+448.01589 p_{t 1}^{2}-422.14618 p_{t 1}+156.85117
$$

$$
C_{P}^{d v o}=402.1153 p_{t 1}^{5}-4006.05631 p_{t 1}^{4}+15686.88113 p_{t 1}^{3}-30157.54742 p_{t 1}^{2}+28457.0162 p_{t 1}-10560.43274
$$




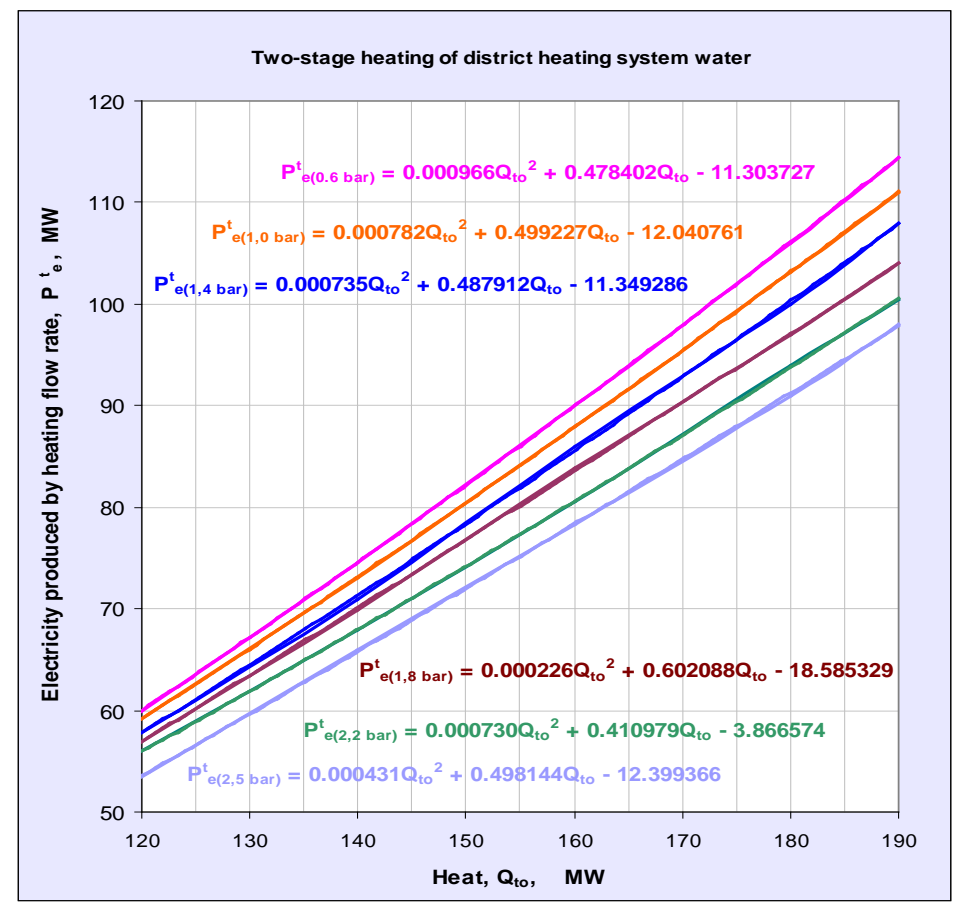

Fig. 4. Heat-supply operating regime of the T-100-110/130-3 CHP turbine - dependence of electricity produced by heat-supply flow on heat and on the pressure in the upper heating extraction at two-stage heating of system water [3]

\section{The equations reliability}

Equations given in the paper are checked by comparing the results of the calculation obtained by the program using the measured data obtained on the actual turbine during operation for the same ambient air temperatures. The results of comparisons for the regime with two-stage heating of the returned system water are given in Table 1.

Table 1. Comparison of the calculation results obtained by the program with the measured data obtained on the actual turbine during operation for the same ambient air temperatures for the regime with two-stage heating of the district heating system water [3]

\begin{tabular}{llllllll}
\hline $\begin{array}{l}\text { Ambient air } \\
\text { temperature, }\end{array}$ & Program & \multicolumn{9}{c}{$\begin{array}{c}\text { Measured data obtained } \\
\text { during operation }\end{array}$} & $\begin{array}{c}\text { Electricity } \\
\text { deviation }\end{array}$ \\
\cline { 2 - 8 }$\vartheta_{v . z .}$ & $\left(P_{e}\right)_{\text {prog }}$ & $\left(D_{\text {turdo }}^{t}\right)_{\text {prog }}$ & $\left(D_{\text {kon }}^{t}\right)_{\text {prog }}$ & $\left(D_{\text {tur }}\right)_{m}$ & $\left(p_{t 1}\right)_{m}$ & $\left(P_{e}\right)_{m}$ & $4 P_{e}$ \\
$4^{0} \mathrm{C}$ & $84 \mathrm{MW}$ & $278 \mathrm{t} / \mathrm{h}$ & $62 \mathrm{t} / \mathrm{h}$ & $340 \mathrm{t} / \mathrm{h}$ & $1.0 \mathrm{bar}$ & $82 \mathrm{MW}$ & $+2.4 \%$ \\
$2^{0} \mathrm{C}$ & $92 \mathrm{MW}$ & $317 \mathrm{t} / \mathrm{h}$ & $83 \mathrm{t} / \mathrm{h}$ & $400 \mathrm{t} / \mathrm{h}$ & $1.4 \mathrm{bar}$ & $91 \mathrm{MW}$ & $+1.1 \%$ \\
$0^{0} \mathrm{C}$ & $94 \mathrm{MW}$ & $352 \mathrm{t} / \mathrm{h}$ & $68 \mathrm{t} / \mathrm{h}$ & $420 \mathrm{t} / \mathrm{h}$ & $1.6 \mathrm{bar}$ & $93 \mathrm{MW}$ & $+1.1 \%$ \\
$-2^{0} \mathrm{C}$ & $96 \mathrm{MW}$ & $387 \mathrm{t} / \mathrm{h}$ & $53 \mathrm{t} / \mathrm{h}$ & $440 \mathrm{t} / \mathrm{h}$ & $1.8 \mathrm{bar}$ & $95 \mathrm{MW}$ & $+1.0 \%$ \\
$-4^{0} \mathrm{C}$ & $98 \mathrm{MW}$ & $423 \mathrm{t} / \mathrm{h}$ & $37 \mathrm{t} / \mathrm{h}$ & $460 \mathrm{t} / \mathrm{h}$ & $2.0 \mathrm{bar}$ & $97 \mathrm{MW}$ & $+1.0 \%$ \\
$-6^{0} \mathrm{C}$ & $101 \mathrm{MW}$ & $458 \mathrm{t} / \mathrm{h}$ & $32 \mathrm{t} / \mathrm{h}$ & $490 \mathrm{t} / \mathrm{h}$ & $2.2 \mathrm{bar}$ & $99 \mathrm{MW}$ & $+2.0 \%$ \\
$-8^{0} \mathrm{C}$ & $100 \mathrm{MW}$ & $461 \mathrm{t} / \mathrm{h}$ & $29 \mathrm{t} / \mathrm{h}$ & $490 \mathrm{t} / \mathrm{h}$ & $2.4 \mathrm{bar}$ & $98 \mathrm{MW}$ & $+2.0 \%$ \\
$-10^{0} \mathrm{C}$ & $99 \mathrm{MW}$ & $472 \mathrm{t} / \mathrm{h}$ & $18 \mathrm{t} / \mathrm{h}$ & $490 \mathrm{t} / \mathrm{h}$ & $2.4 \mathrm{bar}$ & $97 \mathrm{MW}$ & $+2.0 \%$ \\
$-12^{0} \mathrm{C}$ & $99 \mathrm{MW}$ & $472 \mathrm{t} / \mathrm{h}$ & $18 \mathrm{t} / \mathrm{h}$ & $490 \mathrm{t} / \mathrm{h}$ & $2.4 \mathrm{bar}$ & $97 \mathrm{MW}$ & $+2.0 \%$ \\
$-14^{0} \mathrm{C}$ & $99 \mathrm{MW}$ & $472 \mathrm{t} / \mathrm{h}$ & $18 \mathrm{t} / \mathrm{h}$ & $490 \mathrm{t} / \mathrm{h}$ & $2.4 \mathrm{bar}$ & $97 \mathrm{MW}$ & $+2.0 \%$ \\
\hline
\end{tabular}

Since in case of heat-supply operation regime on the turbine it is not possible to measure only the electricity obtained on the basis of heat-supply steam extractions but rather the total electricity, in this case the electricity obtained on the basis of the total steam flow through a turbine is compared with total electricity that is given by the program. As can be seen from 
Table $1, \mathrm{t}$ he results obtained by using the program provide a good match with the measurement data obtained on the actual turbine: the deviation is in the range of $+1.0 \%$ to $+2.4 \%$. It can also be seen that the sum of computed steam flow of heat extraction and computed steam flow to the condenser fully agree with the measured steam flow at the entry into the turbine. Therefore, it can be concluded that the results of the calculations provided by the program are reliable, including therefore also the equations based on these results.

Single equations are valid only for a specific turbine, but by taking into consideration single specific characteristics similar equations can be obtained for different CHP turbines.

\section{Conclusion}

The paper presents some results of the original computational program by means of which it is possible to calculate all the operating regimes of T-100-110/130-3 CHP turbine. The energy characteristics, which are obtained by translating the previously designed uniform operating regime diagram from graphical to analytic form, are built in the algorithm of the program. The computational program is successfully used in the Cogeneration Plant Zagreb (TE-TO Zagreb) for the prediction of the relevant parameters of single operating regimes with the aim of work optimization of the CHP turbine. Simultaneously it makes possible to investigate the different operating regimes with the aim of improving their economy (e.g. the introduction of stage-wise heating of system water of district heating). The algorithm is also applicable for other types of CHP turbines, and by taking into consideration single specific characteristics, a program for calculating the operating regimes of the concrete turbine is obtained (condensing turbines with one or two controlled steam extractions; turbines with back-pressure, including the turbines with back-pressure and controlled steam extraction). The comparison of the results of the calculations provided by the program with the measured data obtained on the actual turbine during operation indicates that the equations presented in the paper are reliable, i.e. their accuracy is acceptable for the engineering application.

\section{References}

[1] S. Ghafghaziet et al., A multicriteria approach to evaluate district heating system options, Applied Energy 87, 2010, pp. 1134-1140.

[2] A. Joelsson and L. Gustavsson, District heating and energy efficiency in detached houses of different size and construction, Applied Energy 86, 2009, pp. 126-134.

[3] P. Jukić, Improvement of operating regimes of CHP turbine, M.Sc. Thesis, Faculty of Mechanical Engineering and Naval Architecture, University of Zagreb, 2005, Zagreb, [in Croatian].

[4] E.I. Benenson and L.S. Ioffe, CHP steam turbines, Energiya, 1986, Moscow [in Russian].

[5] A. Kostyuk and V. Frolov, Steam and gas turbines, Mir Publishers, 1988, Moscow.

[6] A.D. Truhniy, Stationary steam turbines. Energoatomizdat, 1990, Moscow [in Russian].

[7] H. Bloch and M. Singh, Steam turbines: design, application and re-rating, McGraw-Hill Professional, 2008, New York.

[8] J.H. Horlock, Combined power plants: including combined cycle gas turbine (Ccgt) plants, Krieger Publishing Company, 2001, New York.

[9] I.S. Ertesvag, Exergetic comparison of efficiency indicators for combined heat and power (CHP), Energy 32, 2007, pp. 2038-2050. 